\title{
A EXPERIMENTAÇÃO NO ENSINO DE BIOLOGIA: CONTRIBUIÇÕES DA TEORIA DO ENSINO DESENVOLVIMENTAL PARA A FORMAÇÃO DO PENSAMENTO TEÓRICO
}

\author{
Edna Sousa de Almeida Miranda ${ }^{1}$ \\ Sandra Valéria Limonta Rosa²
}

\section{Resumo}

A teoria histórico-cultural (VIGOTSKI, 2001) e a teoria do ensino desenvolvimental (DAVIDOV, 1988) subsidiaram a problematização da relação entre a experimentação científica em laboratório e a aprendizagem dos conceitos de Biologia, destacando as possíveis contribuiçóes da teoria do ensino desenvolvimental para a formação do pensamento teórico dos estudantes. $\mathrm{O}$ objetivo geral desta investigação foi analisar e compreender como a experimentação científica no ensino de Biologia pode contribuir para o desenvolvimento do pensamento teórico. Para isso, adotaram-se como procedimentos metodológicos a pesquisa bibliográfica sobre a produção do conhecimento a respeito da experimentação científica no ensino da Biologia e a realização de um experimento didático-formativo com alunos do primeiro ano do Ensino Médio do IFMT, campus Bela Vista, na cidade de Cuiabá-MT. A realização do experimento didático-formativo, apesar de suas limitações, indicou que a teoria do ensino desenvolvimental tem muito a contribuir para com a organização e realização do ensino escolar na disciplina de Biologia e também em outras áreas do conhecimento.

Palavras-chave: Ensino de Biologia. Ensino desenvolvimental. Pensamento teórico.

1 Mestra em Educação pela UFG, técnica em Assuntos Educacionais do IFMT Campus Cuiabá Cel. Octayde Jorge da Silva. E-mail: edininhaalmeida@gmail.com

2 Pós-doutora em Educação pela PUC-GO, professora da Faculdade de Educação da UFG. E-mail: sandralimonta@gmail.com 


\section{Introdução}

Este artigo apresenta a pesquisa de mestrado desenvolvida no Programa de Pós-Graduação em Educação da UFG, intitulada "A experimentação no ensino de biologia: contribuiçóes da teoria do ensino desenvolvimental para a formação do pensamento teórico".

Partindo do entendimento da necessidade de ambientes de laboratórios no ensino não somente de Biologia, mas também Física e Química, o aporte teórico desta pesquisa (DAVIDOV, 1988; VIGOTSTKI, 2001) possibilita a compreensão de que, apesar de a experimentação científica em laboratório ser considerada um método eficiente no ensino dos conteúdos escolares, isto não significa que possa levar a aprendizagem correta dos conceitos científicos. Por isso, é importante que os professores compreendam como a experimentação científica pode interferir no ensino dos conceitos científicos de modo a assegurar o desenvolvimento pleno dos jovens estudantes.

Fundamentada nos pressupostos da teoria histórico-cultural de Lev S. Vigotski, a teoria do ensino desenvolvimental proposta por Vassili V. Davidov (1988) enfatiza o importante papel da escola no ensino e aprendizagem dos conceitos científicos sob as formas da Ciência, da Arte e da Filosofia, aprendizagem que por sua vez impulsiona o desenvolvimento psíquico das crianças e jovens em idade escolar. Para o autor, o desenvolvimento do pensamento teórico é o tipo de pensamento que promove mudanças qualitativas no intelecto e na personalidade das pessoas.

Deste modo, o objetivo geral desta pesquisa foi analisar e compreender, com base na teoria do ensino desenvolvimental, como a experimentaçáo científica no ensino de Biologia pode ser organizada de forma a contribuir para o desenvolvimento do pensamento teórico dos estudantes do ensino médio. Para isso, a partir dos objetivos específicos, buscou-se problematizar a experimentação científica no ensino de Biologia a partir da pesquisa bibliográfica sobre essa temática nas produçóes acadêmicas da região Centro-Oeste e eventos científicos da área e compreender os fundamentos psicológicos e pedagógicos da teoria do ensino desenvolvimental articulando-os ao ensino de Biologia, visando apontar possíveis contribuiçóes para uma melhor organização do ensino de Biologia no ensino médio.

A fim de alcançar os objetivos supracitados, adotaram-se como procedimentos metodológicos, além da revisão bibliográfica, a realização de um 
experimento didático-formativo em uma turma de primeiro ano no Ensino Médio Integrado do Instituto Federal de Mato Grosso, campus Bela Vista, Cuiabá - MT, o qual consistiu no desenvolvimento de atividades de ensino e aprendizagem fundamentadas na teoria do ensino desenvolvimental de Vassili V. Davidov (1988).

\section{0 ensino de Biologia e a experimentação científica na formação de conceitos: pesquisa bibliográfica}

Ao longo da história da educação brasileira, o ensino de Ciências e Biologia sempre tentou estabelecer-se como dinâmico e inovador, a fim de promover uma educação científica no país. No entanto, a educação em ciências ainda revela-se como um ensino reducionista, prescritivo e pela memorizaçáo de termos e conceitos biológicos, além de utilizar do método científico na abordagem de determinados conteúdos, com um ensino limitado aos livros didáticos (KONDER, 1998; KRASILCHIK, 2000).

Esta concepção tradicional se estende à experimentação científica que, apesar de seu rico potencial didático na aprendizagem de conceitos científicos, tem se limitado a meras observaçóes e comprovaçóes de teorias.

Tais evidências são reforçadas com a pesquisa bibliográfica realizada a partir da análise das produçóes acadêmico-científicas que tratam da experimentação científica no ensino de Biologia na região Centro-Oeste e eventos científicos da área (EREBIO/ENEBIO/ENPEC) ${ }^{3}$ no período de 2011 a 2016, com intuito de fundamentar o objeto de estudo proposto.

Inicialmente, buscaram-se dissertaçóes e teses na região Centro-Oeste (tabela 1), nos programas de pós-graduação de cada região, banco de teses e dissertaçôes da Capes ${ }^{4}$ e também Banco de Dados de Teses e Dissertaçóes (BDTD), totalizando oito produçóes acadêmicas, todas com abordagem de temas abrangendo o ensino de ciências.

$\mathrm{Na}$ região Centro-Oeste foi constatada apenas uma dissertação de mestrado voltada para a área de Biologia, abrangendo a Educação Ambiental na perspectiva da teoria do ensino desenvolvimental.

3 EREBIO (Encontro Regional de Ensino de Biologia); ENEBIO (Encontro Nacional de Ensino de Biologia); ENPEC (Encontro Nacional de Pesquisa em Educação em Ciências).

4 Coordenação de Aperfeiçoamento de Pessoal de Nível Superior (Capes). 
Tabela 1 - Produções científico-acadêmicas encontradas sobre o ensino de Biologia e a experimentação científica

\begin{tabular}{l|c|c}
\hline Produção Científica & Região Centro- Oeste & Outras regiões \\
\hline Dissertação de Mestrado & 6 & 3 \\
Tese de Doutorado & 2 & 1 \\
\hline Total & 8 & 4 \\
\hline
\end{tabular}

Fonte: Elaborado pela autora.

A busca no Banco da Capes e BDTD revelou que, em outras regióes brasileiras, as produçóes acadêmicas ( 4 no total) com temáticas que têm como objeto de pesquisa o ensino da biologia, a teoria histórico-cultural e a teoria do ensino desenvolvimental já se mostram significativas, nas quais se destaca a Universidade Estadual de Maringá (UEM), com dissertaçôes e teses, além de artigos científicos voltados para temáticas semelhantes ao objeto de estudo desta pesquisa.

Em seguida, buscaram-se produçóes científicas apresentadas em eventos da área como Encontro Regional e Nacional de Ensino de Biologia (ERE$\mathrm{BIO} / \mathrm{ENEBIO}$ ), totalizando 42 trabalhos (tabela 2) voltados para a temática da experimentação científica no ensino de Ciências e Biologia abrangendo concepçôes de alunos, professores, estratégias didáticas, entre outros.

No geral, contabilizaram-se 54 trabalhos com relevância para fundamentar o papel da experimentação científica no ensino de biologia e na formação de conceitos científicos.

Tabela 2 - Artigos científicos encontrados em eventos da área sobre o ensino de Biologia e a experimentação científica

\begin{tabular}{l|c}
\hline Evento científico & Produção científica \\
\hline ENEBIO/EREBIO & 32 \\
ENPEC & 10 \\
\hline Total & 42 \\
\hline
\end{tabular}

Fonte: Elaborado pela autora.

Os trabalhos oriundos da pesquisa bibliográfica, assim como as normativas educacionais brasileiras, reforçam a forte presença de um ensino espontaneísta da disciplina de Biologia com uma abordagem superficial dos conteúdos 
escolares, limitando os estudantes a meras definiçóes e classificaçóes dos conceitos, o que pouco contribui para uma aprendizagem de qualidade e o desenvolvimento intelectual dos estudantes.

Do mesmo modo, percebeu-se que a experimentação científica tem sido utilizada em uma concepção empírica da ciência, cujo método científico limita-se a observaçóes simples e comprovaçóes de teorias, negando a dinamicidade da ciência, tão importante à aprendizagem conceitual e o desenvolvimento do pensamento para a compreensáo crítica e consciente do mundo em que vivem (ARAÚJO; RODRIGUES; SILVA, 2013; DAHER; MACHADO; GARCIA, 2015).

Vale destacar que tal concepção tradicional no ensino de Biologia e as dificuldades enfrentadas no uso da experimentação científica estão relacionadas a uma formação inicial deficiente dos professores desta área do conhecimento, o que faz, conforme Konder (1998), com que muitos apenas reproduzam a lógica de sua ciência em sua prática escolar, optando por aulas expositivas restritas aos livros didáticos.

Ademais, na análise das produções acadêmico-científicas percebeu-se uma abordagem voltada para diferentes alternativas metodológicas no intuito de melhorar a qualidade do ensino de Biologia, revelando-se como possíveis tendências nesta área do conhecimento. Entre as alternativas apresentadas percebeu-se uma forte ênfase dada ao conhecimento utilitário (Teoria da Aprendizagem Significativa e perspectiva CTS $^{5}$ ), voltado para a solução de problemas imediatos para atender à lógica do mercado de trabalho.

Tais modelos de ensino já aderidos anteriormente pela legislação brasileira, por exemplo, os PCNs ${ }^{6}$ (BRASIL, 2002) e ainda persistentes nas reformas educacionais atuais, como o novo Ensino Médio (BRASIL, 2016), tornam-se preocupantes por pouco contribuírem ao desenvolvimento de novas formas de pensar e agir e para a transformaçáo da realidade dos jovens estudantes, função social esta da escola na vida das pessoas, concepção defendida por Vassili V. Davidov.

Diante do exposto, a compreensão dos fundamentos teóricos da teoria do ensino desenvolvimental pode subsidiar a unidade entre o conhecimento biológico e pedagógico, para assim superar o ensino tradicional desta disciplina nas escolas e na formação dos licenciandos e fazer da experimentação

5 Ciência, Tecnologia e Sociedade.

6 Parâmetros Curriculares Nacionais. 
científica uma forte tendência nos espaços escolares para ampliação de conhecimentos e o desenvolvimento pleno das pessoas.

\section{Fundamentos epistemológicos, psicológicos e pedagógicos da teoria do ensino desenvolvimental}

A educação escolar tem papel relevante no desenvolvimento intelectual das pessoas. É neste sentido que a escola tem como função social promover o ensino e aprendizagem do conhecimento historicamente acumulado sob as formas da Ciência, Arte e Filosofia, cuja apropriação do saber científico impulsiona o desenvolvimento do pensamento. Tal apropriação é o que assegura ao homem ampliar sua compreensão de mundo e transformar sua realidade.

Fundamentada na concepção do materialismo histórico-dialético, a qual entende o conhecimento como resultado da atividade humana, a teoria histórico-cultural de Lev. S. Vigotski explica o desenvolvimento da mente humana tendo como objetos de estudos a origem e desenvolvimento do psiquismo, processos intelectuais, emoçóes, consciência, atividade, linguagem, desenvolvimento humano e aprendizagem (LIBÂNEO; FREITAS, 2006).

Para Vigotski (2001), a aprendizagem e o ensino são formas universais de desenvolvimento do pensamento, sendo dois processos articulados entre si, formando uma unidade, uma vez que "o bom ensino é aquele se adianta ao desenvolvimento". Nesta relação em que o aprendizado constitui-se como elemento mediador resultado das interaçóes sociais, o autor ressalta que o desenvolvimento humano ocorre da relação com o meio sociocultural: através dos signos por um plano interpsíquico (social) transformam-se as atividades internas de pensamento do sujeito, para um plano intrapsíquico (individual).

Graças ao ensino escolar é possível transformar conceitos mais elementares (pensamento por complexos ou pseudoconceitos) em conceitos novos e complexos (pensamento conceitual). Por meio da linguagem, os signos são responsáveis pela mediação entre os homens e estes com o mundo e permitem que significados transformem-se em atos de pensamento (VIGOTSKI, 2001).

Neste sentido, Vigotski (2001, p. 348) salienta a importante articulação entre conceitos espontâneos e conceitos científicos:

O conceito espontâneo da criança desenvolve de baixo para cima, das propriedades mais elementares e inferiores a supe- 
riores, ao passo que os conceitos científicos se desenvolvem de cima para baixo, das propriedades mais complexas e superiores para as mais elementares e inferiores.

Assim, a interação social inerente ao processo ensino-aprendizagem (professor-aluno-conhecimento) permite que a criança, ao ingressar na escola, transforme seus conceitos espontâneos (oriundos da cultura acumulada historicamente pelo indivíduo nas suas práticas cotidianas) em conceitos científicos (formados de uma organização escolar sistemática), caracterizando uma evolução e revolução no pensamento (VIGOTSKI, 2001; SFORNI, 2004).

Desta relação de interdependência entre conceitos espontâneos e conceitos científicos, Vigotski (2001, p. 329) introduziu a categoria denominada de zona de desenvolvimento proximal (ZDP):

Em colaboração, a criança se revela mais forte e mais inteligente que trabalhando sozinha, projeta-se ao nível das dificuldades intelectuais que ela resolve, mas sempre existe uma distância rigorosamente determinada por lei, que condiciona a divergência entre a sua inteligência ocupada no trabalho que ela realiza sozinha e a sua inteligência no trabalho em colaboração.

É na ZDP que as estratégias didático-pedagógicas devem ser elaboradas pelo professor para que o estudante possa evoluir no aprendizado, transformando o desenvolvimento potencial em desenvolvimento real, reforçando a concepção de que a boa aprendizagem é aquela que sempre está à frente do desenvolvimento.

Para isso, é necessária uma formação docente sólida para que o professor supere o equívoco entendimento do ensino dos conceitos científicos como um prolongamento dos conceitos espontâneos, o qual limita o seu trabalho pedagógico a um ensino verbalista e utilitário do conhecimento, infrutífero ao desenvolvimento pleno dos jovens estudantes.

Esta superação do saber espontâneo em direção ao saber sistematizado é o que irá possibilitar transformaçóes nas atitudes dos sujeitos diante do objeto de estudo, garantindo a eles o desenvolvimento de não uma única forma de pensar, mas muitas capacidades específicas de pensar nas diferentes áreas do conhecimento escolar (VIGOTSKI, 2010). 


\section{A teoria do ensino desenvolvimental}

A teoria do ensino desenvolvimental de Vassili Vassilievich Davidov ${ }^{7}$ (1988) fundamenta-se na concepção do materialismo histórico-dialético do conhecimento e na concepção da teoria histórico-cultural do desenvolvimento humano de Lev Vigotski, a qual enfatiza a importância do ensino escolar na internalização dos conceitos científicos, o qual impulsiona o desenvolvimento psíquico dos estudantes.

Partindo da concepçáo vigotskiana de que o bom ensino se adianta ao desenvolvimento, Davidov (1988) busca estruturar princípios pedagógico-didáticos propondo que a organização didática do ensino escolar seja estruturada a partir da concepção de atividade de estudo desenvolvida por Elkonin. Esta proposta tem sua origem no cenário de reformas educacionais na Rússia na década de 1920, cujas escolas apresentavam forte presença da pedagogia tradicional com um ensino empírico e verbalista considerado insuficiente para a formação que Davidov almejava para os estudantes.

Diante destas constatações de Davidov (1988) em suas pesquisas experimentais ao longo de 25 anos, o autor propóe uma organização adequada do ensino que, por meio da atividade de estudo, possibilita a formação do pensamento teórico e o desenvolvimento omnilateral dos estudantes, no intuito de superar tal modelo de educação escolar que comprometia o processo de aquisição dos conceitos científicos e a qualidade deste desenvolvimento.

De acordo com Freitas e Limonta (2012), a premissa básica da teoria do ensino desenvolvimental é que os métodos de ensino decorrem do conteúdo, ou ainda, dos conceitos que compóem os conteúdos escolares, defendendo a escola e o ensino dos conhecimentos científicos, éticos, estéticos e técnicos como os principais meios de promoção do desenvolvimento psicológico e sociocultural desde a infância.

Vale destacar que o levantamento bibliográfico realizado nesta pesquisa sobre o ensino de Biologia confirmou as constataçóes de Davidov (1988) de que as disciplinas da área das Ciências da Natureza têm apresentado um ensino pautado na concepção empírica do conhecimento. O ensino de Biologia, por exemplo, tem contribuído para a formaçáo do pensamento empírico nos estudantes, por se restringir à descrição, definiçãa e classificação dos objetos

7 Vassili Vassilievich Davydov (1920-1998), psicólogo, pedagogo, filósofo e doutor em Psicologia, pertence à terceira geração de psicólogos russos que pesquisaram o desenvolvimento humano a partir da teoria histórico-cultural de Vigotski. 
ou fenômenos, ocasionando assim uma fragmentação do saber científico. Tal ensino é reflexo de uma formação acadêmica também fragmentada, o que implica um trabalho docente semelhante.

No sentido de superar o pensamento empírico, das meras observaçóes e representaçóes imediatas, Davidov (1988) ressalta a necessidade de uma forma de pensamento organizado, isto é, o pensamento teórico que contribui para o desenvolvimento de todas as formas da consciência social, visto que está entre elas o conhecimento científico. Logo, somente a instrução escolar tem potencial para contemplar uma formação voltada ao desenvolvimento pleno do homem.

Assim, a atividade de estudo se constitui uma etapa importante do desenvolvimento humano, no qual o processo investigativo do objeto deve apresentar um princípio transformador, que possibilite através dos conhecimentos teóricos a apropriação das formas de consciência mais desenvolvidas, como a ciência, a arte, a moralidade, a lei (DAVIDOV, 1988; 1999).

Considerando a influência da atividade social na atividade individual do homem, Davidov (1988) apresenta a periodização da infância fundamentada a princípio por Vigotski e posteriormente desenvolvida por Leontiev e Elkonin. As etapas de desenvolvimento estão associadas a um tipo de atividade principal em que ocasionam mudanças importantes nas características psicológicas do homem.

É por meio de atividade principal que a criança se relaciona com o mundo e, conforme essa relação muda, exigem-se novas reorganizaçóes psíquicas avançando ao estágio de desenvolvimento seguinte (DAVIDOV, 1988; FACCI, 2004). É na adolescência, por exemplo, que o avanço no desenvolvimento intelectual culmina na formação dos verdadeiros conceitos, a qual possibilita mudanças qualitativas na personalidade e nas atitudes ante a realidade.

No processo de domínio do conteúdo das formas desenvolvidas de consciência social (as ciências, arte, moral e leis) em decorrência do pensamento organizado de muitas geraçóes, surge na criança uma atitude em relação à realidade que está associada ao desenvolvimento da consciência e do pensamento teórico juntamente com capacidades como reflexão, análise e planejamento mental. (DAVIDOV, 1988, p. 45). 
A realização da atividade de estudo permite aos estudantes que por meio dos conteúdos escolares possam traçar açóes que resultam em mudanças no seu modo de agir, atuando no seu desenvolvimento. Os conhecimentos adquiridos neste processo de busca científica, devidamente organizado pelo professor, serão utilizados não somente na vida escolar, mas também no mundo em que vive (DAVIDOV, 1988; SFORNI, 2004).

Para contemplar este pensamento mais elaborado, Libâneo e Freitas (2015) salientam a importância do professor ao abordar o objeto do conhecimento, identificar seu aspecto nuclear, sua gênese e história do conceito em busca do princípio geral. Com isso, o professor assegura ao aluno o caminho para aquisição de um novo conceito de modo que possa utilizá-lo na solução de problemas de sua realidade.

Para que esta proposta de ensino desenvolvimental possa contemplar o desenvolvimento pleno dos jovens estudantes, mais uma vez, é preciso uma formação sólida dos professores e de seus formadores na perspectiva de Davidov para que estes também desenvolvam o pensamento teórico. Neste sentido, a concepçáo tradicional de ensino nos cursos de licenciaturas precisa ser superada de modo a assegurar a qualidade cognitiva da aprendizagem conceitual e do pensar com a formação de alunos críticos e assim possibilitar aos professores e seus alunos a transformação da realidade em que vivem.

\section{0 experimento didático: contribuições da proposta de Davidov para o ensino de Biologia}

Organizar o ensino na perspectiva desenvolvimental consiste na utilização de diferentes meios que levem os estudantes a desenvolverem novas capacidades intelectuais e a formarem ativamente o pensamento teórico. Sendo assim, a realização da atividade de estudo dirigida pelo professor motiva a capacidade de aprender, cujas açóes caracterizam-se como investigaçóes que os estudantes realizam enquanto buscam soluçóes para as tarefas propostas que resultam na apropriação dos conceitos estabelecendo relaçóes entre a tarefa e os conceitos estudados.

As açôes de aprendizagem introduzidas por Davidov (1988) revelaram-se como um método especial de pesquisa, a qual propunha a organização dos conteúdos e métodos, de modo a conduzir o pensamento da relação geral para a compreensão das particulares, seja do objeto ou fenômeno estudado. 
Para o autor, a tarefa de estudo é desenvolvida pelos estudantes mediante o cumprimento de determinadas açóes, nas quais cada uma é composta por operaçóes correspondentes em que a estrutura sofre alteraçóes conforme condiçóes concretas de tal tarefa.

Repetidas vezes afirmamos que a tarefa de estudo é desenvolvida mediante o cumprimento de determinadas açóes que passamos a enumerar: Transformaçáo dos dados da tarefa a fim de revelar a relação universal do objeto estudado; Modelação da relação diferenciada em forma objetivada, gráfica ou por meio de letras; Transformação do modelo da relação para estudar suas propriedades em "forma pura"; Construçáo do sistema de tarefas particulares que podem ser resolvidas por um procedimento geral; Controle da realização das açóes anteriores; Avaliação da assimilaçáo do procedimento geral como resultado da solução da tarefa de aprendizagem dada. (DAVIDOV, 1988, p. 99).

Com sua origem na corrente histórico-cultural, o experimento didático-formativo, também denominado de experimento genético-modelador, se apresenta como uma metodologia de pesquisa que permite verificar experimentalmente se o ensino organizado pelo professor a partir dos pressupostos da teoria do ensino desenvolvimental de Davidov (1988) pode avançar no processo de formação do pensamento teórico dos estudantes.

Partindo da possibilidade de superação de um ensino tradicional e empírico ainda táo presente na disciplina de Biologia no Ensino Médio, o experimento didático-formativo foi elaborado com o intuito de analisar o processo de formação de conceitos científicos e a relação aprendizagem-desenvolvimento de uma turma de primeiro período do curso técnico integrado ao nível médio em Meio Ambiente no IFMT, campus Cuiabá - Bela Vista, na cidade de Cuiabá, Mato Grosso.

A escolha do primeiro ano do ensino médio mostrou-se como uma proposta interessante por ser o primeiro contato dos adolescentes com conceitos teóricos específicos da Biologia, que se diferenciam em quantidade e profundidade do que aprenderam ao longo do ensino fundamental na disciplina de Ciências Naturais.

Inicialmente, de acordo com os pressupostos da teoria de ensino desenvolvimental, buscou-se identificar os conceitos fundamentais, denominados por 
Davidov (1988) como conceitos nucleares, para a compreensão da disciplina de Biologia em sua totalidade, a fim de contribuir na formação do pensamento teórico. Desse modo, definiu-se como conceito nuclear o conteúdo escolar sobre célula, delimitando-se ao conceito de divisão celular.

Assim como o conceito de célula, a divisão celular tem sido abordada em uma perspectiva tradicional de ensino, sendo considerado um conteúdo muito abstrato, de difícil compreensão, que se torna pouco significativo no processo educativo para os estudantes (SILVEIRA et al., 2011). Neste sentido, o uso da experimentação científica, associado aos conhecimentos teóricos, pode minimizar tal formato fragmentado do ensino de conteúdos biológicos importantes como a divisão celular.

O experimento didático-formativo foi realizado no mês de junho do ano de 2017, em oito sessóes de 50 minutos cada, totalizando 13 horas/aulas. As sessôes foram filmadas pela pesquisadora para posterior análise à luz da teoria histórico-cultural e da teoria do ensino desenvolvimental, buscando identificar os processos de desenvolvimento mental dos estudantes. Os sujeitos da pesquisa foram 23 estudantes do primeiro ano do Curso Técnico Integrado do Instituto Federal de Educação, Ciência e Tecnologia, da cidade de Cuiabá-MT, na faixa etária entre 14 e 15 anos.

Sendo assim, o planejamento do experimento didático-formativo referente ao conceito da divisão celular consistiu na proposição de uma tarefa de estudo, a realizar uma reportagem sobre o processo de divisão celular e aspectos da saúde humana. Organizados em grupos de cinco alunos, para cumprir tal tarefa, estes jovens precisaram realizar as seis açóes de estudo de Davidov (1988), cuja apropriação gradativa de conceitos importantes sobre a divisão celular subsidiou a solução da tarefa proposta pelo professor. A turma demostrou entusiasmo diante da possibilidade de realizar atividades diferentes das quais está habituada no cotidiano das aulas.

Entre tais açóes de estudo a serem desenvolvidas para o cumprimento da tarefa proposta, utilizou-se da análise e o debate de documentários e imagens, a participação ativa em aulas práticas no laboratório, o planejamento e a realização da reportagem. Para Davidov (1988), realizar a ação é realizar o movimento do pensamento do abstrato para o concreto e esse movimento é o próprio processo de desenvolvimento do pensamento teórico. 


\section{Análise do experimento didático-formativo: aspectos importantes}

A realização do experimento didático-formativo revelou alguns aspectos importantes e norteadores da teoria do ensino desenvolvimental. Uma organizaçáo do ensino na perspectiva desenvolvimental tem o professor como importante mediador entre aluno e conhecimento quando cria situaçóes de aprendizagem que conduzem os estudantes ao movimento do pensamento do geral ao particular, do coletivo ao individual.

Para transcender o ensino espontaneísta ainda táo presente nas escolas e contemplar a formação do pensamento teórico, este professor precisa ter domínio e conhecimento aprofundado dos conteúdos escolares para a compreensão da essência do conceito pelos estudantes. Como já explicitado, isto implica uma formação inicial sólida e permanente dos professores e os formadores destes professores para que possam também alcançar o desenvolvimento pleno em prol da transformação pessoal e da educação brasileira.

O desenvolvimento do experimento didático-formativo revelou que os estudantes de ensino médio estão habituados com um ensino voltado para o imediatismo e utilitarismo do conhecimento, cujas exigências são mínimas para o desenvolvimento cognitivo e a compreensão dos fenômenos estudados. O ensino de Biologia ainda está pautado em uma concepção positivista e fragmentada, o que compromete o ensino dos conceitos científicos e a expansão do pensamento científico, teórico em tal área do conhecimento.

Com a apropriação gradativa dos conceitos biológicos no decorrer do experimento didático-formativo objetivou-se minimizar a compreensão simples e aparente inicial e conduzir para a formação de procedimentos mentais como análise, reflexão e síntese, importantes à compreensão da Biologia em sua totalidade e ao entendimento da realidade em que vivem.

Neste sentido, o professor é essencial na superação desta representação imediata em direção à formação de um pensamento crítico e mais elaborado, conforme Vigotski (2001) e Davidov (1988), somente possível por meio do ensino dos conceitos científicos para o desenvolvimento pleno destes indivíduos, sendo este o grande desafio da escola no mundo contemporâneo. 
Outro aspecto importante neste processo investigativo foi a atividade em grupo, cuja busca coletiva pela solução da tarefa propiciou a interação e mediação entre as diferentes zonas de desenvolvimento dos alunos participantes em tal processo. É nessa interação do grupo que os estudantes, ao apropriarem-se dos conhecimentos, vão superando suas dificuldades de modo a adquirir mais autonomia nas discussóes e questionamentos sobre o objeto estudado, neste caso, o processo de divisão celular, assim contribuindo para a aprendizagem e desenvolvimento individual.

Vale destacar que a adolescência constitui-se como um momento difícil para os jovens estudantes, pelas exigências intelectuais e sociais impostas pelo meio sociocultural no qual estão inseridos. Assim, neste momento de crise, é muito importante o uso de métodos de ensino que auxiliem os ensinos dos conteúdos escolares para que tais estudantes sejam motivados para os estudos (ANJOS, 2014). Dessa forma, a organização do ensino pela tarefa de estudo desdobrada em seis açôes de estudo pode contribuir para que o adolescente sinta-se motivado e confiante em relação às atividades escolares.

Esta motivação no decorrer da realização do experimento didático-formativo foi confirmada pelo entusiasmo e a grande curiosidade, manifestados pelos estudantes a respeito de outros conceitos que iam sendo necessários para compreensão do processo de divisão celular, à medida que realizavam as açóes para cumprir a tarefa.

A ação de estudo que envolveu a experimentação científica em laboratório (fotografia 1) apresentou como proposta a observação em lâmina permanente das células da raiz da cebola, a fim de que os estudantes pudessem compreender a dinâmica do processo de mitose, buscando minimizar as dificuldades dos níveis de abstração de tal conceito, que é apresentado nos livros didáticos como algo tão distante da realidade destes jovens. Além disso, buscou-se contemplar o entendimento de que a ciência, neste caso, a Biologia, é construída historicamente, enfatizando-se as grandes descobertas científicas em prol da humanidade.

Tal metodologia confirmou seu rico potencial didático, imprescindível para uma visão ampla e consciente dos fenômenos biológicos, neste caso, o processo de divisão celular, revelando ainda a importância da unidade entre conhecimento teórico e método de ensino. 
Fotografia 1 - Atividade de estudo em laboratório

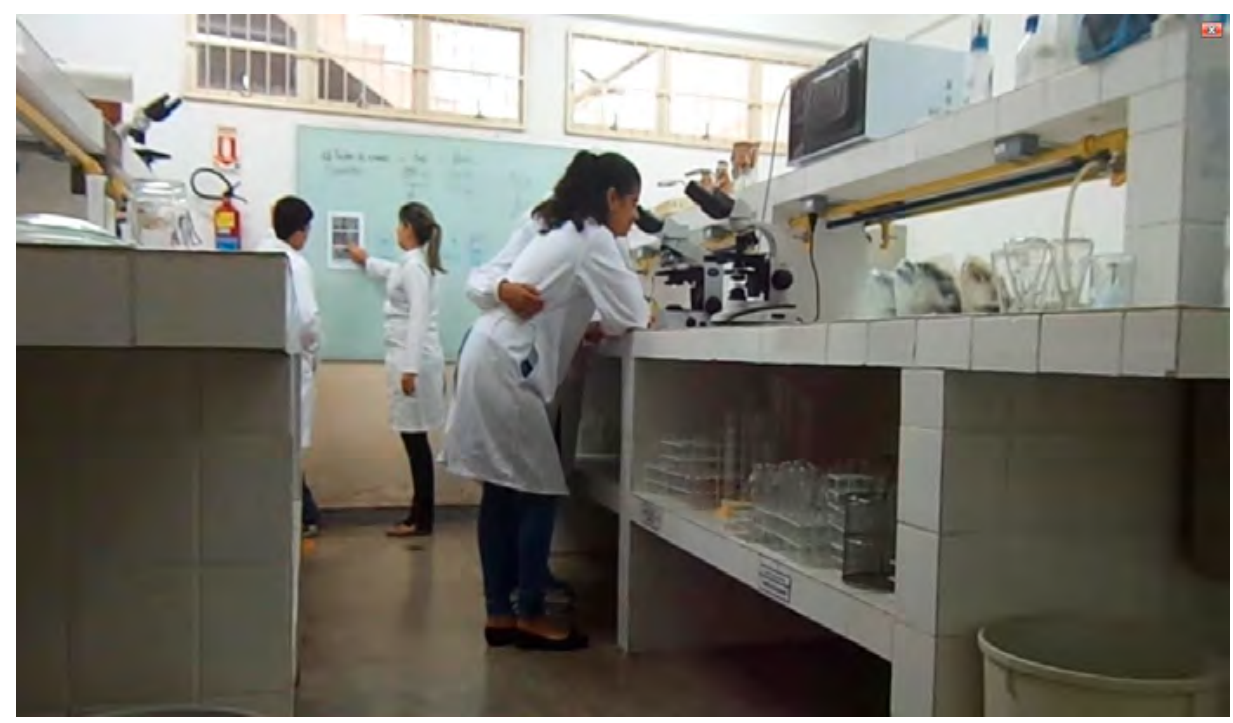

Fonte: Acervo da pesquisa.

A interação social inerente a esta prática investigativa, além de motivar os estudantes, também contribuiu para a formação dos conceitos científicos e o desenvolvimento cognitivo dos estudantes. No entanto, a atividade de estudo em laboratório nos mostrou que é preciso cuidado para que tal atividade não se limite a uma experiência diferente com a compreensão aparente do conceito em estudo, sendo ainda mais relevante o papel mediador do professor na superação desse pensamento empírico ao desenvolvimento do pensamento teórico.

Isto porque, conforme constatado em pesquisa bibliográfica, o uso da experimentaçáo científica no ensino da Biologia ainda é mínimo pelos professores devido à formaçáo inicial docente limitada, associada à falta de condições físicas e estruturais adequadas para realização da aula prática, além da intensa jornada do ofício de ensinar. Com isto, os professores limitam-se ao improviso com a comprovação de teorias, reforçando o método científico utilizado historicamente pelos cientistas (BORGES, 2002).

Apesar de tais dificuldades se confirmarem na realidade escolar, como o espaço pequeno e a presença de apenas um microscópio em bom estado, foi possível observar que, além do encantamento e do entusiasmo dos estudantes por estarem fora da sala de aula, muitos conseguiram observar, descrever e 
explicar os fenômenos biológicos, caracterizando a "verdadeira aprendizagem" defendida pela teoria do ensino desenvolvimental.

A teoria apresentada por Davidov (1988) destaca a relevância da história do conceito estudado para uma compreensão dialética do conhecimento. Esta abordagem lógica e histórica, além de permitir a compreensão da ciência como construção humana e não uma ciência empírica de verdades absolutas, se revela como promissora no processo investigativo do conceito de divisáo celular, de modo a contribuir aos estudantes um movimento do pensamento que ocorre do plano geral para o particular e vice-versa, em busca de identificar o aspecto nuclear do objeto em estudo.

Contudo, foi possível verificar o desenvolvimento do conceito de divisão celular, demonstrando uma peculiar evolução no pensamento dos estudantes de uma compreensão aparente para uma compreensão mais elaborada de tal processo biológico com a realização da tarefa de estudo. Tal evidência confirmou o intuito do experimento didático-formativo que busca reconhecer, por meio da atividade de estudo, a qualidade da aprendizagem e o desenvolvimento psíquico dos jovens estudantes.

Além disso, perceberam-se indícios de um pensamento mais elaborado a partir do conceito nuclear e de outros conceitos que internalizaram no decorrer do experimento no momento em que apresentaram as reportagens uns para os outros, demonstrando, por exemplo, capacidade de análise e síntese quanto ao conteúdo estudado. Para Davidov (1988), procedimentos mentais desenvolvidos a partir da apropriação dos conceitos científicos sobre a divisão celular serão utilizados não somente na vida escolar, mas também no meio sociocultural de tais jovens.

Apesar das limitaçóes entre planejamento e sua aplicação, o experimento didático-formativo revelou-se como uma metodologia profícua para a pesquisa de novas formas de organização do ensino, a fim de contribuir para a produção de conhecimentos importantes à qualidade da educação brasileira e firmar o papel do ensino escolar devidamente organizado pelo professor para a formação do pensamento conceitual e o desenvolvimento pleno de nossos jovens estudantes. 


\section{Considerações Finais}

Esta pesquisa, ao propor uma organização do ensino na perspectiva desenvolvimental, por meio da realização do experimento didático-formativo, revelou-se como uma proposta desafiadora ao ensino das disciplinas de Ciências da Natureza, neste caso, a Biologia, para que ocorra a construçáo do processo histórico do conhecimento enfatizando o movimento dialético existente nos objetos e fenômenos biológicos. O professor e seu papel mediador são fundamentais para a correta apropriação dos conceitos científicos e o desenvolvimento pleno de tais sujeitos.

A ação de estudo desenvolvida em laboratório contribuiu para superar a compreensão aparente do processo de divisão celular dos estudantes, indicando uma peculiar evolução para uma compreensão mais elaborada de tal processo biológico. Isto porque não é a experimentação em si que promove o desenvolvimento do pensamento e sim a forma como a experimentaçáo se insere na tarefa de estudo, que relaçóes e mediaçóes as açóes de experimentação em laboratório possuem com as outras açôes.

Considerando os retrocessos impostos à educação brasileira, mais do que nunca é preciso um ensino escolar que preze pela qualidade do pensamento dos estudantes e pela formação de sujeitos críticos, éticos e transformadores da realidade. Para isso, intensas pesquisas acerca da proposta inovadora de Davidov (1988) são necessárias em benefício do desenvolvimento pleno das pessoas, para que as discussóes sobre esta concepção desenvolvente de ensino e sua possível implementação a médio e longo prazos, assim possam ganhar espaço e serem assumidas pelos sistemas de ensino, na formação continuada de professores e pelos cursos de licenciatura.

\section{REFERÊNCIAS}

ANJOS, Ricardo Eleutério dos. O papel da educação escolar no desenvolvimento da personalidade do adolescente. Nuances: estudos sobre Educação, São Paulo, v. 25, n. 1, p. 228-246, jan./abr. 2014. Disponível em: http://revista.fct.unesp.br/index.php/Nuances/ article/viewFile/2941/2529. Acesso em: 4 set. 2017.

ARAÚJO, Macilene Pereira de; RODRIGUES, Evanize Custódio; DIAS, Márcia Adelino da Silva. Importância da Experimentaçáo no Ensino de Biologia. In: ENCONTRO REGIONAL SUL DE ENSINO DE BIOLOGIA (EREBIO), 2013. 
BORGES, A. T. Novos rumos para o laboratório escolar de ciências. Caderno Brasileiro de Ensino de Física, v. 21, edição especial, p. 9-30, 2004.

BRASIL. Medida Provisória no 746, de 22 de setembro de 2016. Diário Oficial da Uniáo. Disponível em: http://www.planalto.gov.br/ccivil_03/_ato2015-2018/2016/Mpv/mpv746. htm. Acesso em 2 dez. 2016.

- Ministério da Educação. Secretaria de Educação Média e Tecnológica. PCN + Ensino médio: orientaçóes educacionais complementares aos Parâmetros Curriculares Nacionais Ciências da Natureza, Matemática e suas Tecnologias. Brasília, 2002.141 p.

DAHER, Alessandra Ferreira Beker; MACHADO, Vera de Mattos; GARCIA, Joelma dos Santos. Atividades Experimentais no ensino de Ciências: o que expóe o banco de dissertaçôes e teses da CAPES. In: ENCONTRO NACIONAL DE PESQUISA EM EDUCAÇÃO EM CIÊNCIAS (ENPEC), 2015.

DAVÍDOV, Vassíli Vassilievitch. O que é atividade de estudo. Revista «Escola inicial», n. 17 , p. $1-7$, ano 1999 .

Problemas do Ensino Desenvolvimental - a experiência da pesquisa teórica e experimental na psicologia. Texto traduzido do espanhol por José Carlos Libâneo e Raquel A. M. da Madeira Freitas, para uso didático, na disciplina: Didática na perspectiva histórico-cultural, no PPGE. Universidade Católica de Goiás. Moscú: Editorial Progreso, 1988.

FACCI, Marilda Gonçalves Dias. A periodização do desenvolvimento psicológico individual na perspectiva de Leontiev, Elkonin e Vigotski. Caderno Cedes, Campinas, v. 24, n. 62, p. 64-81, abr. 2004. Disponível em: http://www.cedes.unicamp.br . Acesso em: 17 abr. 2017.

FREITAS, Raquel Aparecida Marra da Madeira; ROSA, Sandra Valéria Limonta. A educação científica da criança: contribuiçóes da teoria do ensino desenvolvimental. Linhas Críticas, Brasília, DF, v. 18, n. 35, p. 69-86, jan./abr. 2012. Disponível em: http://portal.mec.gov. $\mathrm{br} /$ index.php?option=com_docman \&view=download $\&$ alias $=48601-\mathrm{mp}-746$-ensino-medio-link-df\&category_slug=setembro-2016-pdf\&Itemid=30192. Acesso em: 10 dez. 2016.

KONDER, O. Ensino de Ciências no Brasil: um breve resgate histórico. In: CHASSOT, A.; OLIVEIRA, J. R. (Org.). Ciência, ética e cultura na educaçáo. São Leopoldo: Ed. UNISINOS, 1998. p. 25.

KRASILCHIK, M. Reformas e Realidade: o caso do ensino de Ciências. Sáo Paulo em Perspectiva, v. 14, n. 1, p. 85-93, 2000. Disponível em: http://www.scielo.br/pdf/spp/ v14n1/9805.pdf. Acesso em: 2 dez. 2016.

LIBÂNEO, José Carlos; FREITAS, Raquel A. M. M. Vasili Vasilyevich Davydov: a escola e a formação do pensamento teórico-científico. In: Ensino desenvolvimental: vida, pensamento e obra dos principais representantes russos. 2. ed. Uberlândia: EDUFU, 2015. p. 327-362.

Vygotsky, Leontiev, Davydov: três aportes teóricos para a Teoria Histórico-Cultural e suas contribuições para a Didática. In: CONGRESSO BRASILEIRO DE HISTÓRIA DA 
EDUCAÇÃO, 4, 2006, Goiânia. Disponível em: <http://www.sbhe.org.br/novo/congressos/ cbhe $4 /$ individuais-coautorais/eixo03/Jose $\% 20$ Carlos $\% 20$ Libaneo\%20e\%20Raquel\%20 A.\%20M.\%20da\%20M.\%20Freitas\%20-\%20Texto.pdf>. Acesso em: 22 jun. 2016.

SFORNI, Marta Sueli Faria. Aprendizagem Conceitual e Organizaçáo do Ensino: contribuiçôes da Teoria da Atividade. Araraquara: JM Editora, 2004.

SILVEIRA, Gabriele Dachi, et al. Percepçáo das diferentes estruturas celulares por alunos egressos do ensino fundamental. In: ENCONTRO REGIONAL SUL DE ENSINO DE BIOLOGIA (EREBIO). Londrina, Paraná, 2011.

VYGOTSKI, Lev S. A Construçáo do pensamento e da linguagem. São Paulo: Martins Fontes, 2001.

. Aprendizagem e desenvolvimento intelectual na idade escolar. In: LURIA, Alexander Romanovich; LEONTIEV, Alex N. Linguagem, Desenvolvimento e Aprendizagem/Lev Semenovich Vigotskii. Traduçáo de Maria da Pena Villalobos.11. ed. Sáo Paulo: Ícone, 2010. p. 103-118. 